\title{
GMR
}

\section{Isolation and characterization of microsatellite markers for Dendranthema morifolium (Asteraceae) using next-generation sequencing}

\author{
W.-J. Yuan ${ }^{1 *}$, S. Ye ${ }^{2 *}$, L.-H. Du1 , S.-M. Li ${ }^{1}$, X. Miao ${ }^{2}$ and F.-D. Shang ${ }^{2}$ \\ ${ }^{1}$ Institute of Chinese Materia Medica, Henan University, Kaifeng, China \\ ${ }^{2}$ College of Life Sciences, Henan University, Kaifeng, China \\ *These authors contributed equally to this study. \\ Corresponding author: F.-D. Shang \\ E-mail: 376995519@qq.com
}

Genet. Mol. Res. 15 (4): gmr. 15048765

Received May 6, 2016

Accepted July 11, 2016

Published October 5, 2016

DOI http://dx.doi.org/10.4238/gmr.15048765

Copyright (C) 2016 The Authors. This is an open-access article distributed under the terms of the Creative Commons Attribution ShareAlike (CC BY-SA) 4.0 License.

ABSTRACT. Dendranthema morifolium (Asteraceae) is a perennial
herbaceous plant native to China. A long history of artificial crossings
may have resulted in complex genetic background and decreased
genetic diversity. To protect the genetic diversity of $D$. morifolium
and enabling breeding of new D. morifolium cultivars, we developed
a set of molecular markers. We used pyrosequencing of an enriched
microsatellite library by Roche 454 FLX+ platform, to isolate $D$.
morifolium simple sequence repeats (SSRs). A total of 32,863 raw
reads containing 2251 SSRs were obtained. To test the effectiveness
of these SSR markers, we designed primers by randomly selecting
100 novel SSRs, and amplified them across 60 cultivars representing
five different petal shape groups. Sixteen SSRs were polymorphic
with the number of alleles ranging from 6 to 19 , and their expected
and observed heterozygosities ranging from 0.477 to 0.848 , and 0.250

Genetics and Molecular Research 15 (4): gmr.15048765 
to 0.804 , respectively. The polymorphism information content ranged from 0.459 to 0.854 and the inbreeding coefficient ranged from -0.119 to 0.759 . An unweighted pair-group method arithmetic average analysis was performed to survey the phylogenetic relationships of these 60 cultivars and five clusters were identified. These markers can be used for investigating genetic relationships and identifying elite alleles through linkage and association analyses.

Key words: SSR; Roche 454; Phylogenetic relationship; Dendranthema morifolium

\section{INTRODUCTION}

Dendranthema morifolium (Asteraceae) is a perennial herbaceous plant native to China. Its flowers have been used in traditional Chinese medicine for centuries. D. morifolium has been cultivated in China and Japan for at least 3000 years. Breeding through multiple artificial crossings has led to the formation of a large number of D. morifolium cultivars, including cutflower, potted, garden, and ground-cover types (Zhang et al., 2011). A long history of artificial crossing and selection might result in a complex genetic background and decreased genetic diversity (Khaing et al., 2013). To protect the genetic diversity of $D$. morifolium and breed new D. morifolium cultivars, a set of molecular markers should be developed for investigating this species' genetic diversity, examining the genetic relationships of its cultivars, and identifying elite alleles through linkage and association analyses (Yamasaki et al., 2005; Khaing et al., 2013). Simple sequence repeats (SSRs) are considered excellent molecular markers for their abundance, high mutation rates, co-dominance, and relative ease of scoring (Kalia et al., 2011; Yuan et al., 2015; Zhao et al., 2016). SSRs are frequently used to survey phylogenetic relationships and select loci associated with agronomic traits in D. morifolium cultivars (Chen et al., 2016). Previous studies have reported some D. morifolium SSR markers (Moe et al., 2011; Khaing et al., 2013; Liu et al., 2015; Shim et al., 2015). However, the limited number of SSR markers available for $D$. morifolium fails to meet the requirements for genetic diversity evaluation, as well as linkage and association analyses. In this study, we used the Roche 454 FLX+ platform to obtain SSR markers from an enriched library for D. morifolium. These novel SSRs were then used to analyze the genetic relationships of 60 major D. morifolium cultivars from Kaifeng.

\section{MATERIAL AND METHODS}

\section{Plant material and DNA extraction}

All D. morifolium samples were collected from Henan University campuses. The 60 cultivars represented five different petal shape groups (Table 1 and Figure 1). Vouchers

are deposited in the herbarium of Institute of Chinese Materia Medica in Henan University (Herbarium accession No. HCMM-201-260). Genomic DNA was extracted from fresh leaves using genomic DNA extraction kit v. 3.0 (TaKaRa, Dalian, China) following the manufacturer protocol.

Genetics and Molecular Research 15 (4): gmr.15048765 
Table 1. Information on the 60 Dendranthema morifolium cultivars used in the study.

\begin{tabular}{|c|c|c|c|c|c|}
\hline No. & Accessions & Petal shape & No. & Accessions & Petal shape \\
\hline 1 & Shuiqi & Flat & 31 & Wanguanjinzhu & Tubular \\
\hline 2 & Fenshiba & Flat & 32 & Chixianjinzhu & Tubular \\
\hline 3 & Mohe & Flat & 33 & Xingshitu & Tubular \\
\hline 4 & Jinbeidahong & Flat & 34 & Wuguangshise & Tubular \\
\hline 5 & Qiujiewanhong & Flat & 35 & Jinzhongzhenyu & Tubular \\
\hline 6 & Nijinbao & Flat & 36 & Huowu & Tubular \\
\hline 7 & Lvmudan & Flat & 37 & Qiansiwanlv & Tubular \\
\hline 8 & Yipinhong & Flat & 38 & Zhuyi & Tubular \\
\hline 9 & Zixiuqiu & Flat & 39 & Zisongzhen & Tubular \\
\hline 10 & Xiaohonggui & Flat & 40 & Caihumeiyu & Tubular \\
\hline 11 & Yuezhiguang & Flat & 41 & Taohuaxian & Tubular \\
\hline 12 & Chunrijianshan & Flat & 42 & Yulingguan & Tubular \\
\hline 13 & Guohuaxueshan & Flat & 43 & Huangxiangli & Tubular \\
\hline 14 & Fenghuolun & Spoon & 44 & Guandongdaxia & Tubular \\
\hline 15 & Biyugoupan & Spoon & 45 & Shizhangzhulian & Tubular \\
\hline 16 & Qiushuichangliu & Spoon & 46 & Gudufochen & Tubular \\
\hline 17 & Baixiangli & Spoon & 47 & Dahongtuogui & Anemone \\
\hline 18 & Huangpingpang & Spoon & 48 & Zituogui & Anemone \\
\hline 19 & Fenhuangxiaori & Spoon & 49 & Huanshuifengui & Anemone \\
\hline 20 & Tangyuaoshi & Spoon & 50 & Huanshuimingzhu & Anemone \\
\hline 21 & Xiangyunwuhe & Spoon & 51 & Ruizhugong & Anemone \\
\hline 22 & Taizhentu & Spoon & 52 & Oufentuogui & Anemone \\
\hline 23 & Yizhinongyan & Spoon & 53 & Yuemingxingxi & Anemone \\
\hline 24 & Shibafenghuan & Spoon & 54 & Qianshouguanyin & Abnormal \\
\hline 25 & Denghongjiulv & Spoon & 55 & Fenluhua & Abnormal \\
\hline 26 & Xiaguangsishe & Spoon & 56 & Yucuilongzhao & Abnormal \\
\hline 27 & Zongchanfochen & Spoon & 57 & Zilongzhao & Abnormal \\
\hline 28 & Zivunfeiyue & Spoon & 58 & Jinlongzhao & Abnormal \\
\hline 29 & Shengguanghongshanhu & Tubular & 59 & Baimaoci & Abnormal \\
\hline 30 & Baiou & Tubular & 60 & Jinfenghuanchao & Abnormal \\
\hline
\end{tabular}
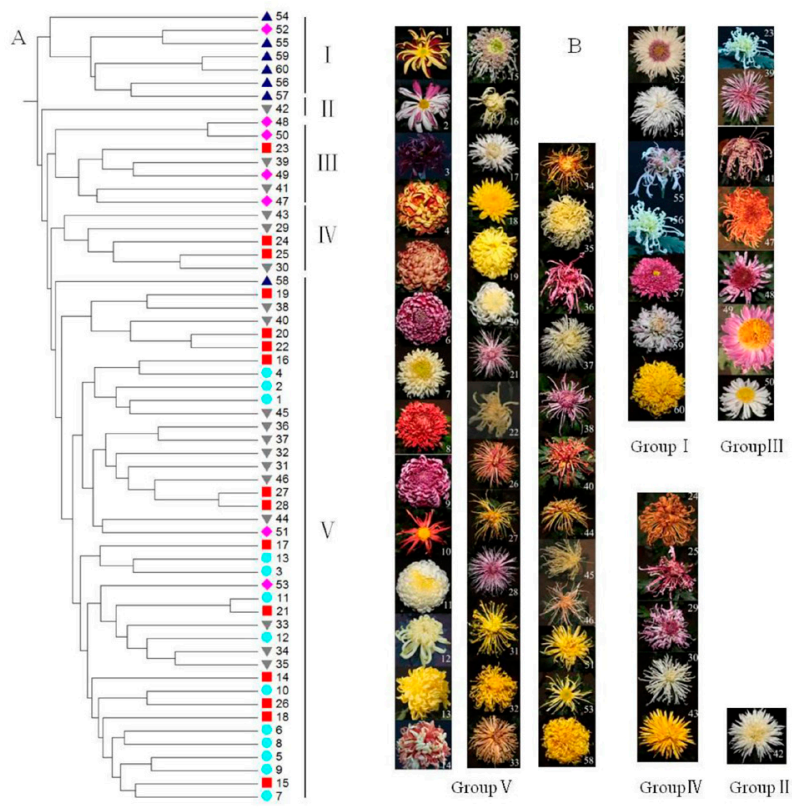

Figure 1. Phylogenetic analysis of 60 Dendranthema morifolium cultivars using 16 SSR markers. A. Dendrogram of 60 D. morifolium cultivars resulting from UPGMA cluster analysis. B. Images of the flowers of D. morifolium cultivars in each assigned group. Blue arrowhead, gray arrowhead, red square, pink diamond, and light blue circle stand for Abnormal, Tubular, Spoon, Anemone, and Flat petal types, respectively. 


\section{DNA sequencing and microsatellite locus search}

Approximately $2 \mu \mathrm{g}$ genomic DNA was digested and separated on a $2 \%$ agarose gel. Fragments of 400-700 bp were extracted. Forward (EcoRI: 5'-CTCGTAGACTGCGTACC-3', MseI: 5'-GACGATGAGTCCTGAG-3') and reverse (EcoRI: 5'-AATTGGTACGCAGTCTAC GAG-3', MseI: 5'-TACTCAGGACTCATCGTC-3') adapters were mixed to prepare doublestranded adapters. Hybridization of biotinylated oligonucleotides $\left[(\mathrm{AG})_{10},(\mathrm{AC})_{10},(\mathrm{AAC})_{8}\right.$, $(\mathrm{ACG})_{8},(\mathrm{AAG})_{8},(\mathrm{ACAT})_{6},(\mathrm{ATCT})_{6}$, and $\left.(\mathrm{AGG})_{8}\right]$ and adapter-ligated genomic DNA was performed. Enrichment libraries were purified using the amplicon library preparation protocol. The Lib-L kit and FLX titanium sequencing kit XLR70 (Roche) were used for the library sequencing on the Roche GS-FLX+ system.

MISA v. 1.0 (Thiel et al., 2003) was used to identify SSR loci. The di-, tri-, tetra-, penta-, and hexanucleotide motifs with a minimum of five repeats were considered as SSRs. Primer design parameters were set as follows: length range, 18-24 nucleotides; product size range, 100$500 \mathrm{bp}$; melting temperature, $55-65^{\circ} \mathrm{C}$; GC content, $40-60 \%$; and GC clamps, no more than $3 \mathrm{Gs}$ or Cs in the last five bases at the 3' end using Primer3 (Rozen and Skaletsky, 2000).

\section{Polymerase chain reaction (PCR) amplification and genotyping}

Of the 2251 identified SSR markers, we randomly selected 100 microsatellites and blasted them in NCBI GenBank. No similar sequences were found in published data. Subsequently, the primer pairs of the selected SSRs were used to test primer amplification efficiency. Twenty microliters PCR amplification solution consisting of $50 \mathrm{ng}$ genomic DNA, $0.5 \mu \mathrm{M}$ each primer, and $10 \mu \mathrm{L} 2 \mathrm{X}$ Taq PCR MasterMix $(0.1 \mathrm{U} / \mu \mathrm{L}$ Taq polymerase, $0.5 \mathrm{mM}$ dNTPs, $20 \mathrm{mM}$ Tris$\mathrm{HCl}, \mathrm{pH}$ 8.3). The PCRs were performed using an S1000 thermal cycler (Bio-Rad, USA). The PCR amplification conditions were as follows: pre-denaturation at $94^{\circ} \mathrm{C}$ for $5 \mathrm{~min}$; followed by 35 cycles of denaturation at $94^{\circ} \mathrm{C}$ for $60 \mathrm{~s}$ and $45 \mathrm{~s}$ at the primer-specific annealing temperature; extension at $72^{\circ} \mathrm{C}$ for $90 \mathrm{~s}$; and a final elongation step at $72^{\circ} \mathrm{C}$ for $8 \mathrm{~min}$. The PCR products were separated on $8 \%$ native polyacrylamide gels and visualized by silver nitrate staining.

\section{Data analysis}

The polymorphism information content (PIC) was estimated using Cervus v. 3.0.7 (Kalinowski et al, 2007). PopGene v. 1.32 (Yeh et al., 2000) was used to analyze the number of alleles per locus $\left(N_{\mathrm{A}}\right)$, expected heterozygosity $\left(H_{\mathrm{E}}\right)$, observed heterozygosity $\left(H_{\mathrm{O}}\right)$, Shannon's information index $\left(I_{\mathrm{S}}\right)$. The significance of the inbreeding coefficient for each locus was tested using FSTAT v. 2.9.3.2 (Goudet, 1995). The Hardy-Weinberg equilibrium for all loci was calculated using GENEPOP 4.2 (Rousset, 2008). The similarity matrix of Dice's coefficient was used to construct a dendrogram based on the unweighted pair group method arithmetic average (UPGMA) using PowerMaker v. 3.25. The significance of the partitioning of genetic variance among different petal shapes was further estimated by analysis of molecular variance using GENALEX 6.41 (Peakall and Smouse, 2006).

\section{RESULTS AND DISCUSSION}

A total of 32,863 raw sequence reads were obtained, ranging from 347 to $978 \mathrm{bp}$ with

Genetics and Molecular Research 15 (4): gmr.15048765 
an average length of $566 \mathrm{bp}$. Of these raw reads, 2251 were found to contain SSRs and were deposited in GenBank (GenBank accession Nos: KP331842 to KP334092). One hundred SSR primers were randomly selected to design primer pairs and perform PCR amplifications across the 60 D. morifolium cultivars, yielding 16 polymorphic amplification products. A total of 160 bands were amplified, with an average of 10 amplified fragments per primer. Fingerprints of all accessions could be amplified from 6 (JH35) to 19 (JH41) bands per primer pair, and PCR product sizes ranged from 156 to $365 \mathrm{bp}$ (Table 2).

\begin{tabular}{|c|c|c|c|c|c|}
\hline Primer & Primer sequence $\left(5^{\prime}-3^{\prime}\right)$ & Repeat motif & $\mathrm{Ta}\left({ }^{\circ} \mathrm{C}\right)$ & Allele size (bp) & GenBank accession No. \\
\hline JH19 & $\begin{array}{l}\text { F:GGAGGGTTTGAAAACAAGCA } \\
\text { R:ATCGCTATTACCATCCGCAC }\end{array}$ & $(\mathrm{AGAT})_{14}$ & 63 & $296-348$ & KP331860 \\
\hline $\mathrm{JH} 25$ & $\begin{array}{l}\text { F:AGCCTTTTGGAGACGAACAA } \\
\text { R:CGACGAAGAAGATGAAGACG }\end{array}$ & $(\text { ATCTTC })_{10}$ & 65 & $233-305$ & KP331866 \\
\hline JH35 & $\begin{array}{l}\text { F:TTTTTCATCCTCTGGTTGCC } \\
\text { R:CCCGATGCCATATTATCCAC }\end{array}$ & $\left(\right.$ CCTTTT $_{5}$ & 60 & $294-336$ & KP331876 \\
\hline JH39 & $\begin{array}{l}\text { F:GAACAAAGGGTTTGATCAAGATG } \\
\text { R:GGGGCTCAAGAGTGGAATA }\end{array}$ & $(\mathrm{GA})_{14}$ & 63 & $190-212$ & KP331880 \\
\hline JH40 & $\begin{array}{l}\text { F:GTGACACGTGGCTTCTCTGA } \\
\text { R:CCAACCCATTCATCTCTCTTC }\end{array}$ & $(\mathrm{GA})_{21}$ & 58 & $289-307$ & KP331881 \\
\hline JH41 & $\begin{array}{l}\text { F:AAACAGCACAAACCCAAAGG } \\
\text { R:CTTACACCGCAAAAGAAGGC }\end{array}$ & $(\mathrm{GA})_{8}(\mathrm{AG})_{13}$ & 60 & 156-199 & KP331882 \\
\hline JH42 & $\begin{array}{l}\text { F:TCTTGACAAAGACGAAGACGAA } \\
\text { R:GCACCTCTACCCCATCAACA }\end{array}$ & $(\text { GACGAT })_{15}$ & 60 & $242-342$ & KP331883 \\
\hline JH47 & $\begin{array}{l}\text { F:TATCCACGGCCCATAGAAAG } \\
\text { R:GAAGGAGGGACCCTGTAGGA }\end{array}$ & $(\mathrm{GT})_{9}$ & 62 & $312-334$ & KP331888 \\
\hline JH56 & $\begin{array}{l}\text { F:AGGAGTGATAGTGCACGGCT } \\
\text { R:CCAAGGTCTCATTCGATGCT }\end{array}$ & $(\mathrm{GTT})_{10}$ & 56 & $244-268$ & KP331897 \\
\hline JH57 & $\begin{array}{l}\text { F:CCCATTTCCTTTTGTTGGTG } \\
\text { R:CCCCATCTATGGTTTTGGAC }\end{array}$ & $(\mathrm{GTT})_{12}$ & 60 & $240-264$ & KP331898 \\
\hline JH70 & $\begin{array}{l}\text { F:TGAGAGCTTGGTGTGACCTG } \\
\text { R:AGTTAGCGTGAATGTGCCCT }\end{array}$ & $(\mathrm{TG})_{10}(\mathrm{GA})_{18}$ & 64 & $265-295$ & KP331911 \\
\hline $\mathrm{JH} 72$ & $\begin{array}{l}\text { F:CGAGCTTATTTGGTTTTGCC } \\
\text { R:ACGAAAGATCGGAGTAAGCG }\end{array}$ & $(\mathrm{TG})_{13}(\mathrm{ATT})_{5}$ & 57 & $300-342$ & KP331913 \\
\hline JH81 & $\begin{array}{l}\text { F:GCCGATAGACTATTTGGGCA } \\
\text { R:TTGGTATTTCGGCCTCTCAC }\end{array}$ & $(\mathrm{TGG})_{6}(\mathrm{TGT})_{12}(\mathrm{TTG})_{7}$ & 58 & $285-311$ & KP331922 \\
\hline JH86 & $\begin{array}{l}\text { F:CAAATACCTCATGTACCTTAAACCTT } \\
\text { R:ACTACATTTGCTGGGGTTCG }\end{array}$ & $(\mathrm{TGT})_{5}(\mathrm{TAT})_{12}$ & 58 & $337-365$ & KP331927 \\
\hline JH87 & $\begin{array}{l}\text { F:ATGATGAACCACCCGTTTGT } \\
\text { R:TCGTCCAAACCAACAAATCA }\end{array}$ & $(\mathrm{TGT})_{6}(\mathrm{GTT})_{12}$ & 60 & $237-261$ & KP331928 \\
\hline JH99 & $\begin{array}{l}\text { F:AGGAGTGATAGTGCACGGCT } \\
\text { R:CAAGGTCTCGTTCATGCTCA }\end{array}$ & $(\mathrm{TTG})_{9}(\mathrm{TTG})_{12}$ & 63 & $273-297$ & KP331940 \\
\hline
\end{tabular}

F: forward primer; R: reverse primer; Ta: PCR annealing temperature.

The genetic diversity indices are shown in Table 3 . The $H_{\mathrm{E}}$ and $H_{\mathrm{O}}$ ranged from 0.477 to 0.848 and from 0.250 to 0.804 , respectively. The average $H_{\mathrm{E}}$ and $H_{\mathrm{O}}$ were 0.788 and 0.535 , respectively. The $I_{\mathrm{S}}$ and $P I C$ ranged from 1.149 to 2.442 and from 0.459 to 0.854 , respectively. The average $I_{\mathrm{S}}$ was 1.829 (Table 3). The inbreeding coefficient ranged from -0.119 (JH47) to 0.759 (JH86). Five of the 16 loci had negative $F_{\text {IS }}$ values (all $\mathrm{P}>0.05$ ), indicating a slight excess of heterozygotes. Total variance was partitioned into components due to differentiation within and among the five petal shape groups. The overall distribution pattern of molecular variation within the cultivars suggested that approximately $91.0 \%$ of the total variance could be accounted for by the within group component. The remaining $9.0 \%$ of the variation was found among groups. The variance component was shown to be highly significant $(\mathrm{P}<0.05)$.

The UPGMA dendrogram was generated to illuminate genetic relationships among the 60 cultivars (Figure 1). Five main clusters (I to V) were observed. Group I comprised five cultivars of the Abnormal petal group (54, 55, 56, 57, 59, and 60) and one cultivar of the Anemone petal group (52). One cultivar of the Tubular petal group (42) constituted Group II. 
Table 3. Genetic diversity parameters for 60 Dendranthema morifolium cultivars using 16 newly developed microsatellite loci.

\begin{tabular}{l|c|c|c|c|c|c|c}
\hline Primer & $N_{\mathrm{A}}$ & $N_{\mathrm{E}}$ & $H_{\mathrm{E}}$ & $H_{\mathrm{O}}$ & $P I C$ & $I_{\mathrm{S}}$ & $F_{\text {IS }}$ \\
\hline JH19 & 11 & 6.2470 & 0.848 & 0.571 & 0.821 & 2.023 & 0.497 \\
\hline JH25 & 9 & 5.3193 & 0.816 & 0.684 & 0.786 & 1.865 & $0.615^{*}$ \\
\hline JH35 & 6 & 3.9534 & 0.753 & 0.373 & 0.720 & 1.484 & 0.182 \\
\hline JH39 & 9 & 4.9793 & 0.806 & 0.567 & 0.764 & 1.827 & 0.438 \\
\hline JH40 & 9 & 3.9929 & 0.756 & 0.655 & 0.725 & 1.732 & $0.546^{*}$ \\
\hline JH41 & 19 & 7.3290 & 0.871 & 0.552 & 0.854 & 2.442 & 0.488 \\
\hline JH42 & 9 & 4.9057 & 0.804 & 0.707 & 0.776 & 1.851 & $0.638^{*}$ \\
\hline JH47 & 10 & 1.8976 & 0.477 & 0.467 & 0.459 & 1.149 & -0.119 \\
\hline JH56 & 9 & 5.5215 & 0.826 & 0.300 & 0.799 & 1.924 & 0.153 \\
\hline JH57 & 8 & 4.1614 & 0.766 & 0.661 & 0.722 & 1.601 & $0.559^{*}$ \\
\hline JH70 & 12 & 4.5444 & 0.787 & 0.525 & 0.752 & 1.812 & 0.398 \\
\hline JH72 & 14 & 5.1465 & 0.813 & 0.350 & 0.787 & 1.993 & 0.201 \\
\hline JH81 & 9 & 5.8489 & 0.836 & 0.583 & 0.806 & 1.863 & 0.503 \\
\hline JH86 & 9 & 5.0785 & 0.810 & 0.804 & 0.782 & 1.872 & $0.759^{*}$ \\
\hline JH87 & 9 & 6.1909 & 0.846 & 0.250 & 0.819 & 1.962 & 0.113 \\
\hline JH99 & 9 & 4.6690 & 0.793 & 0.517 & 0.765 & 1.854 & 0.393 \\
\hline Mean & 10 & 4.9831 & 0.788 & 0.535 & 0.759 & 1.829 & \\
\hline
\end{tabular}

$N_{\mathrm{A}}$ : allele number; $N_{\mathrm{E}}$ : effective numbers of alleles; $H_{\mathrm{E}}$ : expected heterozygosity; $H_{\mathrm{O}}$ : observed heterozygosity; PIC: polymorphism information content; $I_{\mathrm{S}}$ : Shannon's information index; $F_{\mathrm{IS}}$ : inbreeding coefficient; *Significant deviation from Hardy-Weinberg equilibrium.

Group III consisted of four cultivars of the Anemone petal group, two cultivars of the Tubular petal group, and one cultivar of the Spoon petal group. Group IV included three cultivars of the Tubular petal group and two cultivars of the Spoon petal group. Group V contained the remaining 40 cultivars. The clusters were inconsistent with the petal shape grouping (Figure 1), indicating that traditional classification based on petal shapes does not reflect the true phylogenetic relationships of these cultivars.

The present study provides 16 new SSR markers of D. morifolium. These SSRs may facilitate conservation strategy development, evolutionary biology research, and molecular breeding of $D$. morifolium. Most of the microsatellite markers obtained in the present study however need further validation. Furthermore, constructing of hybrid groups and recording of phenotypic traits are all future studies on D. morifolium, which will enable location of the position of developed SSR markers and construct the linkage map of D. morifolium.

\section{Conflicts of interest}

The authors declare no conflict of interest.

\section{ACKNOWLEDGMENTS}

Research supported by the National Nature Science Foundation of China (\#31270738, \#31500572 and \#31400521).

\section{REFERENCES}

Chen Y, Dai X, Hou J, Guan H, et al. (2016). DNA fingerprinting of oil camellia cultivars with SSR markers. Tree Genet. Genomes 12: 7. http://dx.doi.org/10.1007/s11295-015-0966-7

Goudet J (1995). FSTAT (version 1.2): A computer software to calculate F-statistics. J. Hered. 86: 485-486.

Genetics and Molecular Research 15 (4): gmr.15048765 
Liu H, Zhang QX, Sun M, Pan HT, et al. (2015). Development of expressed sequence tag-simple sequence repeat markers for Chrysanthemum morifolium and closely related species. Genet. Mol. Res. 14: 7578-7586. http://dx.doi. org/10.4238/2015.July.13.1

Kalia RK, Rai MK, Kalia S, Singh R, et al. (2011). Microsatellite markers: an overview of the recent progress in plants. Euphytica 177: 309-334. http://dx.doi.org/10.1007/s10681-010-0286-9

Kalinowski ST, Taper ML and Marshall TC (2007). Revising how the computer program CERVUS accommodates genotyping error increases success in paternity assignment. Mol. Ecol. 16: 1099-1106. http://dx.doi.org/10.1111/ j.1365-294X.2007.03089.X

Khaing AA, Moe KT, Hong WJ, Park CS, et al. (2013). Phylogenetic relationships of chrysanthemums in Korea based on novel SSR markers. Genet. Mol. Res. 12: 5335-5347. http://dx.doi.org/10.4238/2013.November.7.8

Moe KT, Ra SB, Lee GA, Lee MC, et al. (2011). Distribution and frequency of SSR motifs in the Chrysanthemum SSRenriched library through 454 pyrosequencing technology. Korean J. Int. Agric. 23: 546-551.

Peakall R and Smouse PE (2006). GENALEX 6: genetic analysis in Excel. Population genetic software for teaching and research. Mol. Ecol. Notes 6: 288-295. http://dx.doi.org/10.1111/j.1471-8286.2005.01155.x

Rousset F (2008). genepop'007: a complete re-implementation of the genepop software for Windows and Linux. Mol. Ecol. Resour. 8: 103-106. http://dx.doi.org/10.1111/j.1471-8286.2007.01931.x

Rozen S and Skaletsky H (2000). Primer3 on the WWW for general users and for biologist programmers. In: Bioinformatics methods and protocols: methods in molecular biology (Misener S and Krawetz S, eds.). Humana Press, Totowa, 365386.

Shim EJ, Heo EJ, Yoon MK, Soh EH, et al. (2015). Construction of SSR marker database of Chrysanthemum varieties collected in Korea. Korean J. Breed. Sci. 47: 366-375. http://dx.doi.org/10.9787/KJBS.2015.47.4.366

Thiel T, Michalek W, Varshney RK and Graner A (2003). Exploiting EST databases for the development and characterization of gene-derived SSR-markers in barley (Hordeum vulgare L.). Theor. Appl. Genet. 106: 411-422.

Yamasaki M, Tenaillon MI, Bi IV, Schroeder SG, et al. (2005). A large-scale screen for artificial selection in maize identifies candidate agronomic loci for domestication and crop improvement. Plant Cell 17: 2859-2872. http://dx.doi. org/10.1105/tpc. 105.037242

Yeh FC, Yang R, Boyle TJ, Ye Z, et al. (2000). PopGene 32, Microsoft Windows-based freeware for population genetic analysis, version 1.32. Molecular Biology and Biotechnology Centre, University of Alberta, Canada.

Yuan WJ, Li Y, Ma YF, Han YJ, et al. (2015). Isolation and characterization of microsatellite markers for Osmanthus fragrans (Oleaceae) using 454 sequencing technology. Genet. Mol. Res. 14: 17154-17158. http://dx.doi. org/10.4238/2015.December.16.15

Zhang F, Chen S, Chen F, Fang WM, et al. (2011). SRAP-based mapping and QTL detection for inflorescence-related traits in chrysanthemum (Dendranthema morifolium). Mol. Breed. 27: 11-23. http://dx.doi.org/10.1007/s11032-010$\underline{9409-1}$

Zhao J, Tong YQ, Ge TM and Ge JW (2016). Genetic diversity estimation and core collection construction of Sinojackia huangmeiensis based on novel microsatellite markers. Biochem. Syst. Ecol. 16: 74-80. http://dx.doi.org/10.1016/j. bse.2015.11.015

Genetics and Molecular Research 15 (4): gmr.15048765 